\title{
SCADDOC
}

Infer, Interpret \& Inspire Science

\author{
International Journal of Dentistry and Oral Science (IJDOS) \\ ISSN: 2377-8075
}

\section{Evaluation of Virtual Measurements of Scanned Dental Impressions}

Research Article

de Souza $\mathrm{RO}^{1 *}$, Vogel $\mathrm{CJ}^{2}$, Braga $\mathrm{E}^{2}$, Habib FA²

${ }^{1}$ Laboratory of Pathology and Molecular Biology, Oswaldo Cruz Foundation, Federal University of Bahia, Bahia, Brazil.

${ }^{2}$ School of Dentistry of the Federal University of Bahia, Bahia, Brazil.

Abstract

Introduction: Digital models have been proposed as substitutes for plaster models. Dental arch impression scanning is a rapid and practical approach for digital model obtainment; however, few studies have accessed the accuracy of the method. This study verified the accuracy of virtual measurements obtained with the scanner Ortho Insight 3D, version 5.0 (Motionview Software, LLC, Chattanooga, Tennessee, USA).

Materials And Methods: Total of 26 plaster models belonging to the Bahia Federal University Orthodontic postgraduation program were divided into three groups: G1 (plaster models); G2 (alginate impressions scan) and G3 (plaster models scan). Virtual measurements were compared to the manual by evaluating upper intercanine and intermolar distances and the antero posterior distance between upper left canine and upper left molar. Paired Student $t$ and Lin agreement (5\% of significance level) were employed for the statistical analysis.

Results: Of the evaluated measures, the mean difference ranged from $0.48 \mathrm{~mm}$ to $0.55 \mathrm{~mm}$ when compared G2 and G1. The mean difference ranged from $0.6 \mathrm{~mm}$ to $0.65 \mathrm{~mm}$ between G3 and G1 groups. Comparing the groups G2 and G3 to G1, it was found statistically significant differences between all variables $(\mathrm{p}<0.05)$. There was a substantial agreement $(\rho c$ between $0.95-0.99)$ and almost perfect $(\rho c>0.99)$ for all parameters evaluated.

Conclusion: Despite having existed significant differences between the virtual and physical approaches, substantial and almost perfect agreement between them allow us to suggest that there is accuracy of virtual images obtained from scanned impressions in alginate using the laser scanner Ortho Insight 3D.

Keywords: Dental Models; Imaging Three-Dimensional; Dental Impression Material.

\section{Introduction}

Plaster models are tools of fundamental relevance for diagnose and orthodontic treatment planning [1-3]. Dental models are employed for evaluation of sagital, vertical and transversal dimensions and also for crowding or spacing measurements. However, plaster models present some disadvantages, such as huge space for storage, risk of loss or breakage and possibility of mold proliferation over long term [2].

In this context, it has been proposed the use of digital models as a tool for diagnose and planning for daily orthodontic practice [1, 4]. Digital models do not require physical space for storage, allow easy information exchange among professionals [2] and enable simple and practical digital diagnose setup making [5].

Digital model obtainment can be produced by laser scanning of plaster models [6], impressions [7] or intra oral direct scanning [8]. Digital models extracted from computed tomography has also been reported [7].

Majorly, the published studies have focused on evaluating the accuracy of digital models obtained from plaster models scanning $[6,9,10]$ and few studies have investigated de precision of digital models produced through dental impression scanning $[12,13]$. Therefore, diagnose and treatment planning can be compromised when using tools that are not properly calibrated. The present study thus aimed at evaluating the accuracy of alginate impression-obtained virtual models.

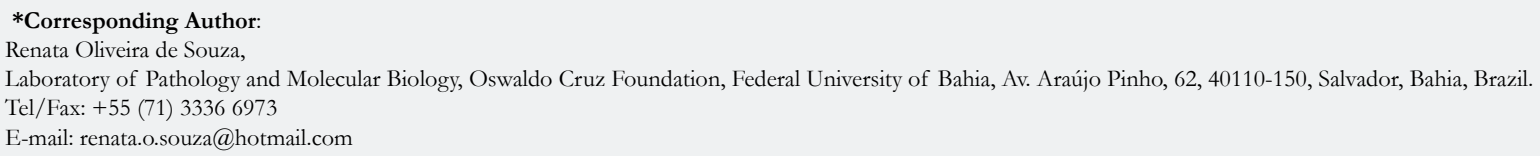

Copyright: de Souza RO ${ }^{\circ}$ 2017. This is an open-access article distributed under the terms of the Creative Commons Attribution License, which permits unrestricted use, distribution and reproduction in any medium, provided the original author and source are credited. 


\section{Material and Methods}

The present study has been approved by the Ethics Committee Board (N. 23087013.3.0000.5024). A pilot study was performed to determine sample size and for that purpose, student- $t$ test was employed to identify $0.2 \mathrm{~mm}$ difference (previously considered as clinical relevant [12]). The power of the test was set at 95\%.

According to sample size determination, 26 dental plaster models were randomly selected among the collection of Orthodontic post-graduation program. The research design comprised 3 distinct groups: G1 (conventional plaster model), G2 (digital model obtained through alginate impression scan) and G3 (digital model obtained through plaster model scan). Group 3 was added in order to access possible dimension alterations throughout the impression/scanning processes. As inclusion criteria for model selection, permanent canines and first molars should be fully erupted.

Plaster models had the canine cuspid and first molar mesio vestibular cuspid perforated with a N.1 stainless steel burr (KG Sorensen Ind. e Com. Ltda., Barueri-SP, Brasil), in order to determine exactly the measurement site. The chosen burr allows the smallest drill possible, according to previous tests. The perforations were performed by a single operator.

The perforated models were then scanned using the laser scan Ortho Insight 3D, version 5.0 (Motionview Software, LLC-Chattanooga, Tennessee, USA). Subsequently, the models were impressed with alginate (Jeltrate plus, Dentsply indústria e comércio Ltda., Petrópolis-RJ, Brasil) and the impressions were immediately scanned and digitized using the same scanning device.

For plaster models measurements, a digital caliperCen-Tech 4"®
(HarborFreight Tools, Calabasas, CA, USA) was employed. For the digital models, the measurements were done using tools provided by the software Motionview (LLC-Chattanooga, Tennessee, USA).

The measurements are described in Figures 1 and 2

A) Intercanine width: transversal segment between upper left and right canine cuspids

B) Intermolar width: transversal segment between upper left and right molars mesio vestibular cuspids

C) Distance between upper left canine and upper left molar: antero posterior segment between upper left canine cuspid and upper left molar mesio vestibular cuspid.

For the present study, paired student-t test and Lin concordance coefficient was employed, using McBride (2005) concordance scale as reference, where values bellow 0.9 are considered poor, from 0.9 to 0.95 moderate, from 0.95 to 0.99 substantial and above 0.99 almost perfect. The confidence interval was set at $95 \%$. Statistical analysis was performed using the R Program version 3.0.2 (R Foundation for StatisticalComputing, Wien, Österreich).

\section{Results}

Mean difference of $0.7 \mathrm{~mm}$ was observed among the groups considering the three measurement accessed (intercanine, intermolar and anteroposterior distance). The difference ranged from 0.48 to 0.55 when compared group G2 to G1 and 0.6 to 0.65 when compared G3 to G1. Mean difference and standard deviation is described in Table 1.

Comparing group G2 and G3 with G1, statistical relevant differences could be detected regarding all variables tested $(\mathrm{p}<0.05)$ (Table 1).

Figure 1. Measurements in plaster models. (A) Distance 1.3-2.3; (B) Distance 2.3-2.6; (C) Distance 2.3-2.6.
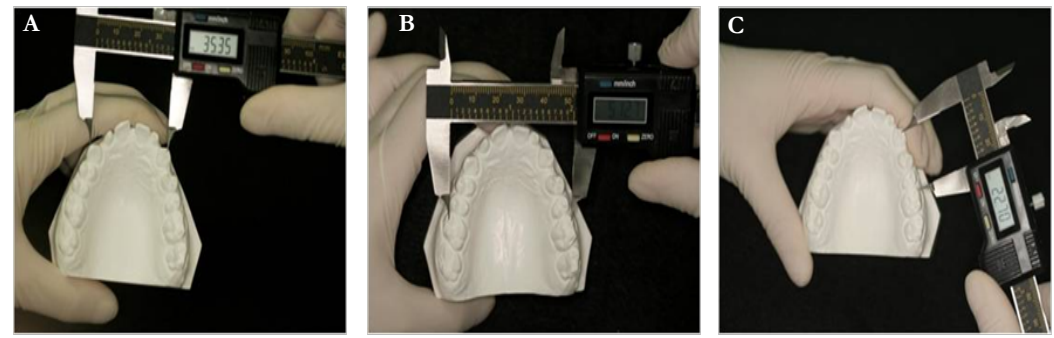

Figure 2. Measurements in virtual models. Distance 1.3-2.3; 1.6-2.6; 2.3-2.6.

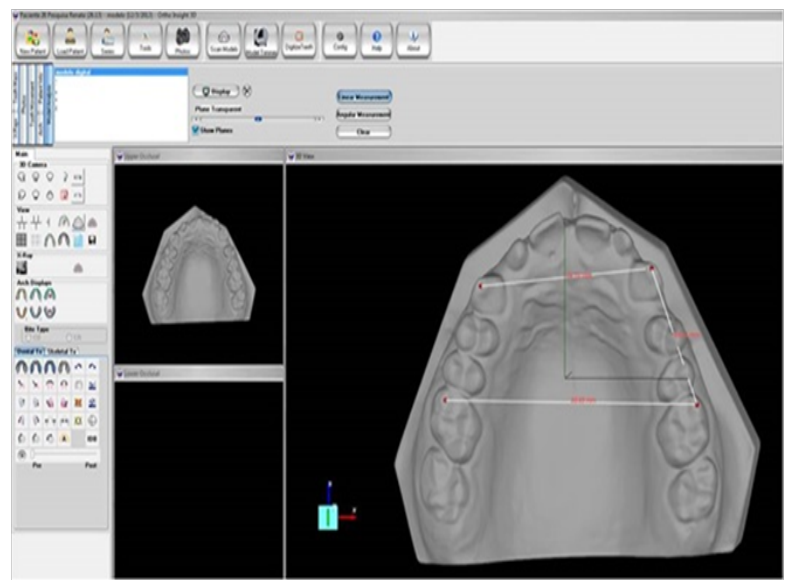


However, a substantial $\left(\rho_{c}\right.$ entre $\left.0,95-0,99\right)$ and almost perfect $\left(\rho_{c}>\right.$ 0.99) concordance was found for the parameters tested when comparing virtual images and plaster models. For instance, anterior posterior distance between upper right canine and first molar showed almost perfect concordance between G1 and G2. Data is displayed in Figure 3.

\section{Discussion}

Digital revolution has enabled the substitution of conventional plaster models for virtual ones and a variety of advantages has been cited in this process $[2,5]$. Virtual models technology has been introduced commercially since the 90's decade $[5,15]$, but as far as the present study could access, no research has been published aiming at evaluating the accuracy of digital models produced through dental impressions applying the laser scanner
Ortho Insight 3D.

The major advantage of obtaining digital model using dental impression is probably the elimination of the plaster pouring and trimming phases [7], making the model production quicker and practical. By using digital models produced through impressions, the orthodontist may optimize the time spent for diagnose and planning and, thus, accelerate the beginning of the treatment. However, dimensional alterations of impression material can occur depending on climate or storage conditions [16-18] making evident the need for excellent material and method processes. As previously mentioned, the virtual image accuracy is directly related to how precise the impression is performed [17]. In the present study, the virtual images were obtained right after the impressions take. Even so, group 3 was added in order to access the occurrence or absence of dimensional alterations, since alginate presents well known stability limitations.

Table 1. Paired t-test. Mean, standard deviation and difference between virtual and manual means $(n=26)$.

\begin{tabular}{|c|c|c|c|c|c|c|c|c|c|c|}
\hline \multicolumn{3}{|c|}{ G1 } & \multicolumn{3}{|c|}{ G2 } & \multirow{2}{*}{ p } & \multicolumn{3}{|c|}{ G3 } & \multirow{2}{*}{ p } \\
\cline { 1 - 1 } Mean & SD & Dif & Mean & SD & Dif. & & Mean & SD & Dif. & \\
\hline $13-23$ & 32.82 & 3.04 & 33.35 & 3.07 & 0.53 & $<0.001$ & 33.45 & 3.07 & 0.63 & $<0.001$ \\
\hline $16-26$ & 48.87 & 4.17 & 49.35 & 4.2 & 0.48 & $<0.001$ & 49.52 & 4.16 & 0.65 & $<0.001$ \\
\hline $23-26$ & 20.81 & 3.04 & 21.36 & 3 & 0.55 & $<0.001$ & 21.41 & 3.04 & 0.6 & $<0.001$ \\
\hline
\end{tabular}

$\mathrm{SD}=$ Standard deviation; Dif.=Difference between media; $\mathrm{p}=$ Statistically different from the manual group (G1).

Figure 3. Graphical representation of the coefficient of agreement of $\operatorname{Lin}$ for the measurements 1.3-2.3 (A) e (B), 1.6-2.6 (C) e (D), 2.3-2.6 (E) e (F).

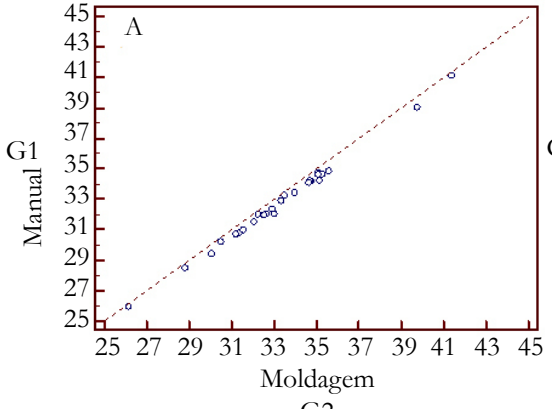

G2

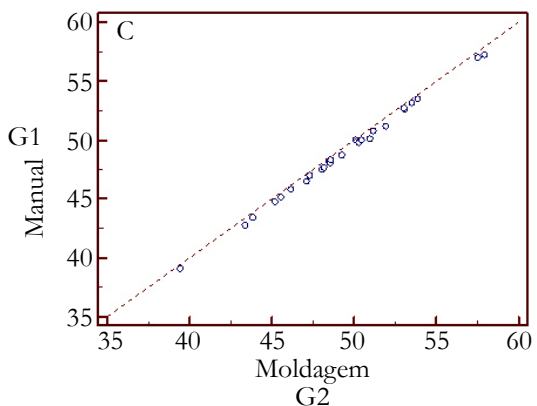

G2

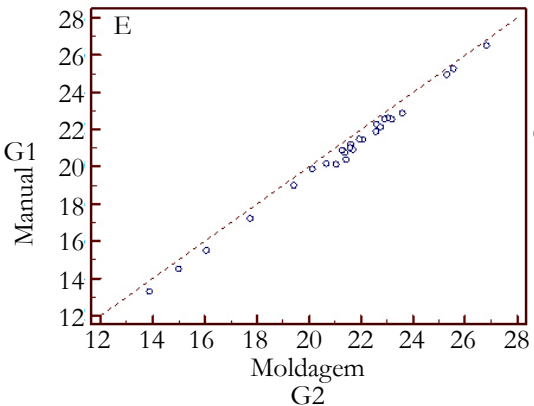

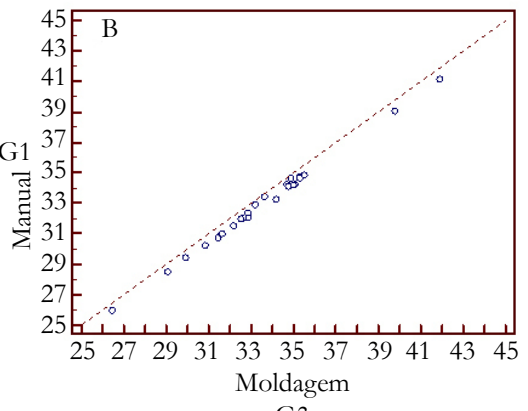

G3

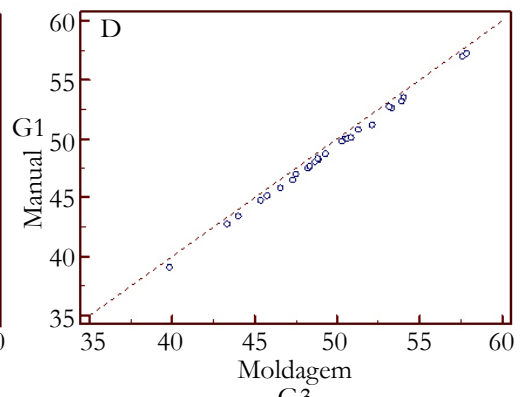

G3

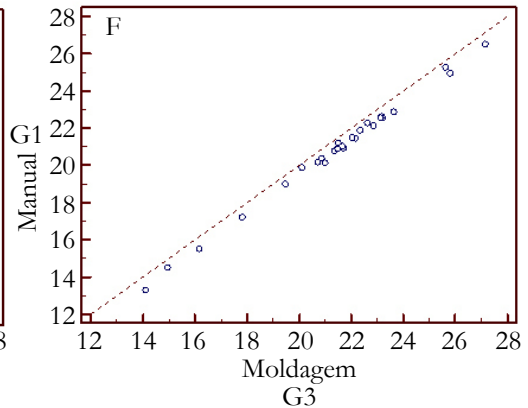


In the present study, when comparing group 2 and 3 with group 1 no statistical relevant differences could be found, clearing that no dimensional alterations occurred due to the process employed. It is thus concluded that alginate impressions provide high quality digital images when scanned immediately after impression. The validity of other time lapses or storage conditions is anticipated.

The clinical significance of eventual discrepancies is a topic of no consensus in the literature $[13,16,20]$. In the present study, $0.2 \mathrm{~mm}$ was considered as clinically significant, as proposed by Wiranto et al., [13]. According to these authors, such difference is enough for compromising the making of appliances based on models produced by prototyping method. QUIMBY et al., [20], found differences smaller than $1 \mathrm{~mm}$ between manual and virtual models, establishing a sufficient sample to demonstrate a difference of up to $2 \mathrm{~mm}$. In the present investigation, differences found were lower than $0.7 \mathrm{~mm}$. It is suggested that this discrepancy has no relevance for diagnose and treatment plan. Digital models produced through impression scans can perfectly reproduce the dental arches and malocclusions present.

A systematic review published by Luu et al., [21] stated that Bolton discrepancy, crowding and arch perimeter were considered clinically significant above $0.7 \mathrm{~mm}$. This evidence possibly corroborates with the use virtual images obtained with Ortho Insight 3D scanner.

Differently from stated by Santoro et al., [23], Torassian et al., [17] and Luu et al., [21], but similarly with research published by Quimby et al., [20], the present study showed that measurements performed in conventional models presented lower measurements when compared to virtual ones. It seems that virtual images are discreetly expanded. This fact has to be critically analyzed because the afore mentioned studies have employed different methodologies.

The present study corroborates with previous researches [20, 23, 24] that have shown significant differences among measurements obtained using plaster or digital models. Despite of these differences, a substantial and almost perfect concordance was obtained between plaster and digital models measurements. Akyalcin et al., [19] stated that a greater concordance will be obtained when a high tolerance among differences is assumed. In the present study, an adequate concordance between virtual and plaster model measurements was observed.

\section{Conclusions}

Based on the results of the present article, considering the substantial and almost perfect concordance between measurements obtained using plaster and digital models constructed through alginate impression scanning performed with Ortho Insight 3D scanner, it is suggested that the digital model is an accurate tool for diagnose and planning in orthodontics.
[3]. Hassan WNW, Othman AS, Chan CS, Ahmad R, Ali SN, Rohim AA. et al. Assessing agreement in measurements of orthodontic study models: Digital caliper on plaster models vs 3-dimensional software on models scanned by structured-light scanner. Am J Orthod Dento facial Orthop. 2016 Nov; 150(5):886-895.

[4]. Mayers M, Firestone AR, Rashid R, Vig KW. Comparison of peer assessment rating (PAR) index scores of plaster and computer-based digital models. Am J Orthod Dentofacial Orthop. 2005 Oct;128(4):431-434.

[5]. Fleming PS, Marinho V, Johal A. Orthodontic measurements on digital study models compared with plaster models: a systematic review. Orthod Craniofac Res. 2011 Feb;14(1):1-16.

[6]. Dalstra M, Melsen B. From alginate impressions to digital virtual models: accuracy and reproducibility. J Orthod. 2009 Mar;36(1):36-41.

[7]. Lightheart KG, English JD, Kau CH, Akyalcin S, Bussa Jr. HI, McGrory $\mathrm{KR}$, et al. Surface analysis of study models generated from OrthoCAD and cone-beam computed tomography imaging. Am J Orthod Dentofacial Orthop. 2012 Jun;141(6):686-693.

[8]. Polido WD. Digital impressions and handling of digital models: the future of dentistry. Dental Press J Orthod. 2010 Oct;15(5):18-22.

[9]. Oliveira DD, Ruellas ACO, Drummond MEL, Pantuzo MCG, Lanna AM. Reliability of three-dimensional digital casts as a diagnostic tool for orthodontic treatment planning: a pilot study. R Dental Press Ortodon Ortop Facial. 2007;12(1):84-93.

[10]. Ender A, Mehl A. Accuracy of complete-arch dental impressions: a new method of measuring trueness and precision. J Prosthet Dent. 2013 Feb;109(2):121-128.

[11]. Chang M, Park SC. Automated scanning of dental impressions. Compu Aid Des. 2009;41(6):404-411.

[12]. Persson ASK, Odén A, Andersson M, Sandborgh-Englund G. Digitization of simulated clinical dental impressions: Virtual three-dimensional analysis of exactness. Dent Mat. 2009 Jul; 25(7):929-936.

[13]. Wiranto MG, Engelbrecht WP, Tutien Nolthenius HE, Meer WJVD, Ren Y. Validity, reliability, and reproducibility of linear measurements on digital models obtained from intraoral and cone-beam computed tomography scans of alginate impressions. Am J Orthod Dentofacial Orthop. 2013 Jan;143(1):140-147.

[14]. McBride GB. A Proposal for Strength of Agreement Criteria for Lin's Concordance Correlation Coefficient. National institute of water \& atmospheric research ltd, Ministry of health; 2005 May. NIWA Client Report: HAM 2005-062. NIWA Project: MOH05201.

[15]. Peluso MJ, JosellSd, Levine SW, Lorei BJ. Digital Models: An Introduction. Semin Orthod. 2004 Sep;10(3):226-238.

[16]. Alcan T, Ceylanoglu C, Baysal B. The Relationship between Digital Model Accuracy and Time-Dependent Deformation of Alginate Impressions. Angle Orthod. 2009 Jan;79(1):30-36.

[17]. Torassian G, Kau CH, English JD, Powers J, Bussa HI, Salas-Lopez AN. Digital models vs plaster models using alginate and alginate substitute materials. Angle Orthod. $2010 \mathrm{Jul} ; 80(4): 662-669$.

[18]. Todd JA, Oesterle LJ, Newman SM, Shellhart WC. Dimensional changes of extended-pour alginate impression materials. Am J Orthod Dentofacial Orthop. 2013 Apr;143(4):S55-63.

[19]. AkyalcinS, Dyer DJ, English JD, Sar C. Comparison of 3-dimensional dental models from different sources: Diagnostic accuracy and surface registration analysis. Am J Orthod Dentofacial Orthop. 2013 Dec;144(6):831-837.

[20]. Quimby ML, Vig KWL, Rashid RG, Firestone AR. The accuracy and reliability of measurements made on computer-based digital models. Angle Orthod. 2004 Jun;74(3):298-303.

[21]. Luu NS, Nikolcheva LG, Retrouvey JM, Flores-Mir C, El-Bialy T, Carey JP, et al. Linear measurements using virtual study models. Angle Orthod. 2012 Nov;82(6):1098-1106.

[22]. Ghislanzoni LTH, Lineberger M, Cevidanes LHS, Mapelli A, Sforza C, McNamara Jr JÁ Evaluation of tip and torque on virtual study models: a validation study. Prog Orthod. 2013 Jul;14(1):14-19.

[23]. Santoro M, Galkin S, Teredesai M, Nicolay OF, Cangialosi TJ. Comparison of measurements made on digital and plaster models. Am J Orthod Dentofacial Orthop. 2003 Jul;124(1):101-105.

[24]. Kim J, Heo G, Lagravère MO. Accuracy of laser-scanned models compared to plaster models and cone-beam computed tomography. Angle Orthod. 2014 May;84(3):1-8.

\section{References}

[1]. Joffe L. Current Products and Practices OrthoCADTM: digital models for a digital era. J Orthod. 2004 Dec 1;31(4):344-347.

[2]. Almeida AM, Lauris RC, Peixoto AP, Gribel BF, Janson G, Garib DG. Modelos digitais em Ortodonia. Pro-Odonto Orto. 2011 May 11;4:55-80. 